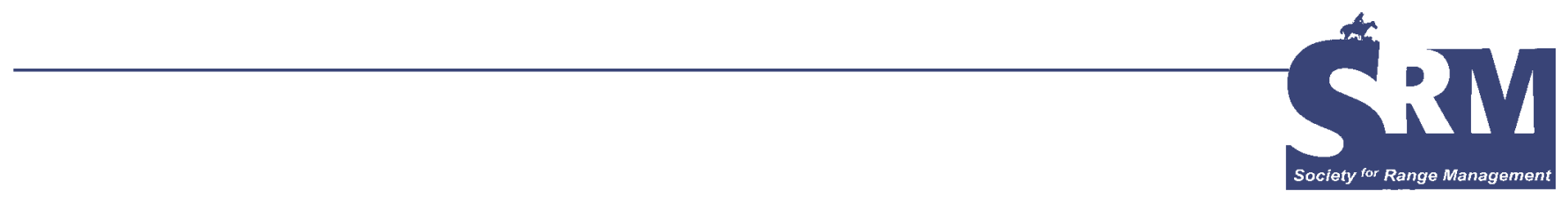

\title{
Climate Change and Ecosystems of Asia With Emphasis on Inner Mongolia and Mongolia
}

\section{By Jay Angerer, Guodong Han, Ikuko Fujisaki, and Kris Havstad}

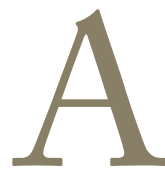

sia is the most populated continent with almost 3.9 billion people. More than half of these people live in rural areas, with many being pastoralists depending on livestock and rangelands for their livelihood. Rangelands occupy over 4.3 billion acres (1.72 billion ha) on the Asian continent, almost $38 \%$ of the total land area (Fig. 1). For some counties, such as Sri Lanka and Laos in southeast Asia, the percentage of rangeland within their borders is relatively minor. However, for many Asian nations, rangelands represent a major land category. Countries such as China, Mongolia, and Russia in northern Asia; and Iran, Afghanistan, and Turkey in western Asia (more commonly referred to as the Middle East) have huge expanses of grasslands and shrublands, and more than $40 \%$ of the land in these nations is categorized as rangeland.

Given the extent and diversity of rangelands across this continent, this paper will focus on an area central to the continent that is still extremely important as a pastoral landscape. The region of Mongolia and Inner Mongolia, China (boxed area within Fig. 1) represents nearly 1.3 billion acres (520 million ha) of rangeland, about $30 \%$ of the rangeland area across this continent. In both Mongolia and Inner Mongolia, livestock production on rangelands is a major source of wealth and well being. Due to large contiguous land areas of rangelands in this region, impacts to the rangeland resource from changing climate can make livestock producers especially vulnerable. In this paper, we will provide an overview of the existing status and uses of rangelands in Mongolia and Inner Mongolia, the projected impacts of climate change, and a discussion on future strategies that can be employed to adaptively manage and reduce vulnerability in this changing environment.

\section{Status and Uses of Mongolian and Inner Mongolian Rangelands \\ Mongolia}

Mongolia is a landlocked country with a land area of over 386 million acres ( 150 million ha), of which over $83 \%$ is rangelands. Agriculture, mostly livestock production, makes up about $20 \%$ of the gross domestic product. Mongolia has a relatively low population compared to other Asian countries with almost 2.6 million people. Livestock producers are generally seminomadic herders who extensively graze their animals in surrounding regions during the spring, summer, and fall, then return to protected camps for the winter months because of the extreme cold.

Mongolia's climate is continental with extremely cold, dry winters and warm summers. A large portion of the country is prone to extreme winter disasters (dzuds), which are periods of intensely cold temperatures accompanied by snow and/or ice. Dzuds that follow periods of summer drought can lead to large losses of livestock because animals are in poor condition going into winter and cannot survive the extreme temperatures. The most recent large-scale occurrence of dzud in Mongolia was during 1999 to 2001 when almost $35 \%$ of the nation's livestock perished.

Mongolia can be classified into six ecological zones that generally follow the north to south elevational gradient. These include the alpine, mountain taiga (forest), forest steppe, steppe, desert steppe, and desert zones. Of these, the forest steppe, steppe, desert steppe, and portions of the desert zone can be classified as rangelands. The forest steppe and steppe zones comprise over half of the land area and have the highest concentration of people and livestock, 


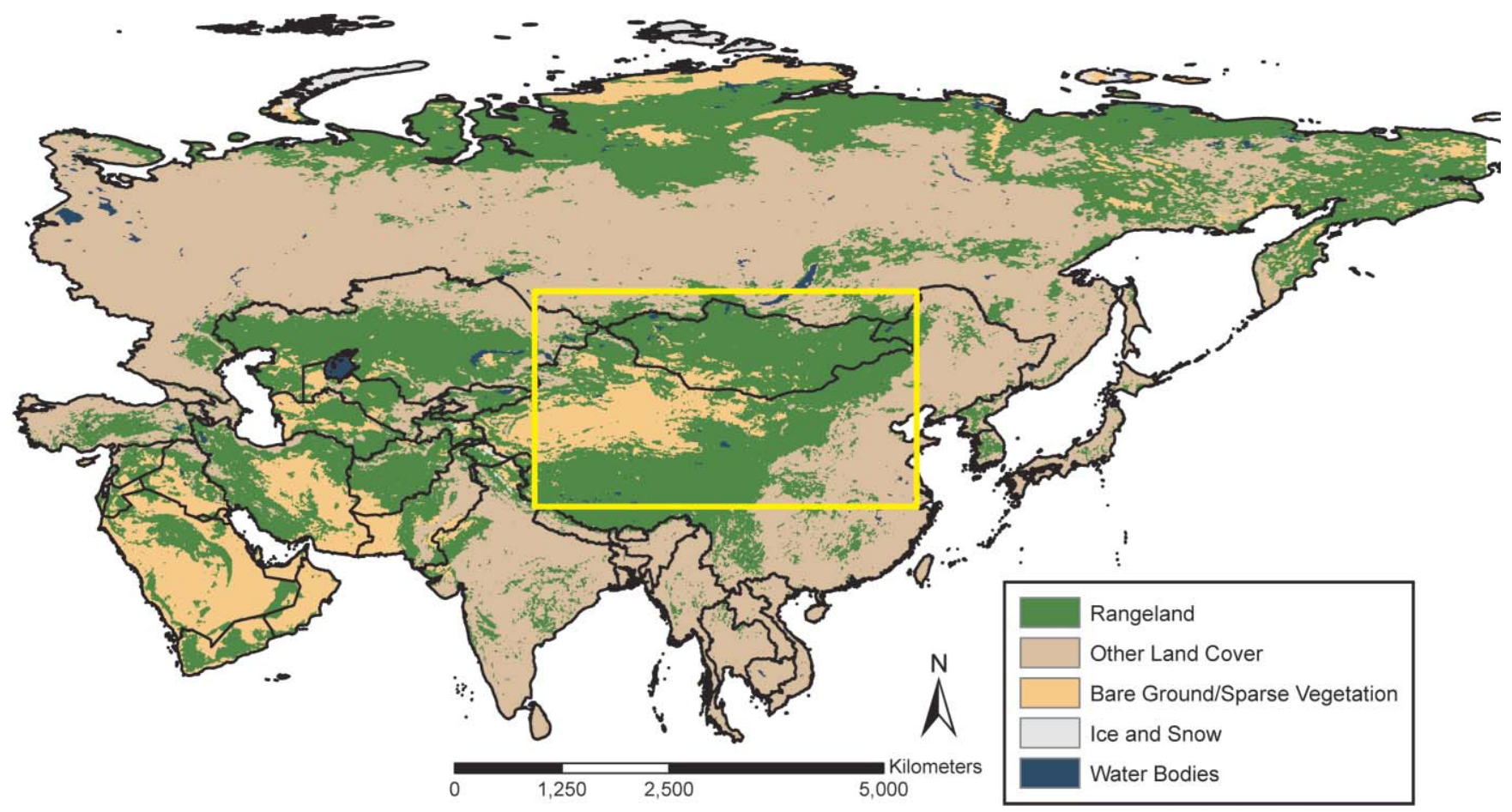

Figure 1. Rangeland areas across the 43 nations of the Asian continent as derived from the Global Land Cover Database using classifications of closed shrublands, woody savannas, savannas, and grasslands as cover classes to define these rangeland areas. The boxed region encloses Mongolia and Inner Mongolia, China, as the region of emphasis.

mainly due to the relatively high forage productivity (530-1,600 pounds $\left.\cdot \mathrm{acre}^{-1} ; 600-1,800 \mathrm{~kg} \cdot \mathrm{ha}^{-1}\right)$. The desert steppe and desert zones occupy approximately $37 \%$ of the land area with productivity that ranges from 25 to 350 pounds $\cdot$ acre $^{-1}\left(30-400 \mathrm{~kg} \cdot \mathrm{ha}^{-1}\right)$.

Since 1990 with the withdrawal and subsequent collapse of the Soviet Union, the livestock industry in Mongolia has transitioned from state-owned collectives to a privatized, market-based system. As of the 2006 census, livestock were comprised of approximately 15.4 million goats, 14.8 million sheep, 2.2 million cattle, 2.1 million horses, and 253 thousand camels. This represented the largest reported number of animals since 1924. In recent years, the number of goats has increased due to a favorable global cashmere market, and cattle numbers have declined.

Rangeland productivity in grazing exclosures has decreased $20-30 \%$ during the last $40 \mathrm{yr}$. This productivity decline has been attributed to recent changes in climate, mainly higher temperatures (overall a $3.2^{\circ} \mathrm{F}$ or $1.8^{\circ} \mathrm{C}$ increase) and lower summer precipitation. The forest steppe and steppe zones were especially susceptible with lower productivity during the spring (April-May). Studies with satellite imagery have shown shifts in ecological zone boundaries with increases in desert steppe land area and declines in forest steppe and steppe. Rangeland degradation near settlements, roads, and water points has been observed and has been attributed to overgrazing due to herders becoming more sedentary, a reduced number of working wells, and less coordination of the spatial distribution of grazing since livestock privatization began in 1990. Although rangeland productivity appears to be declining, livestock numbers have increased 36\% since 2002.

\section{Inner Mongolia}

Approximately $67 \%$ or 195 million acres (78 million ha), of the total land in Inner Mongolia is classified as rangeland. These rangelands are primarily temperate grasslands that are further classified into one of three general types: the mesic meadow steppe with aboveground biomass of 700-2,400 pounds $\cdot$ acre $^{-1}\left(800-2,700 \mathrm{~kg} \cdot \mathrm{ha}^{-1}\right)$ and $28-45$ characteristic species; the drier typical steppe with aboveground biomass of $450-2,225$ pounds $\cdot$ acre $^{-1}\left(500-2,500 \mathrm{~kg} \cdot \mathrm{ha}^{-1}\right)$ and 10-40 characteristic plant species; and the arid desert steppe with aboveground biomass of $280-1,040$ pounds $\cdot \mathrm{acre}^{-1}$ $\left(315-1,170 \mathrm{~kg} \cdot \mathrm{ha}^{-1}\right)$ and $10-17$ characteristic species. The typical steppe is the most prevalent type covering 70 million acres (28 million ha), and occurs between the desert steppe to the west and the meadow steppe to the higher elevations in the east. In addition, there are desert rangelands to the west and woodlands to the east.

China's rapid economic growth over the past decade has certainly impacted the grasslands of Inner Mongolia in a number of significant ways. Population increases and immigration into the region have been substantial, and the population of the region is now over 23 million with several large urban areas with populations greater than 
1 million each. However, much of this area remains rural in nature with relatively low population density. The region has also seen significant development of coal, gas, and oil resources. Specific fossil fuel-rich areas within the region now support relatively new extraction industries with their associated environmental impacts as China's fossil fuel uses escalate in concert with its growing economy. In addition, areas under cultivation have expanded significantly as food and forage production has greatly increased during the last two decades. However, despite these significant changes, the region remains mostly pastoral in nature. The primary provisioning services of meat and fiber generated by grazing livestock within small family operations remain the primary products from these landscapes. Given the growing demand for meat protein with rapid economic growth, these products will likely remain the mainstay of the region for some time.

Unfortunately, due to a combination of factors, including overgrazing, immigration and resulting population increases, and recent decades of climatic stress (generally higher temperatures and lower annual precipitation), these rangelands have been steadily deteriorating at rate of approximately $2 \%$ of the land area annually. The impact of increased, and excessive, stocking rates during the last half century cannot be overstated. Livestock numbers in 1947 were estimated at 8.4 million and by 2003 exceeded 71 million head. Although statistics on the extent of degradation vary, it is generally estimated that productivity in the region has decreased by at least 30\% in recent years. Part of the overgrazing problem has been attributed to a shift away from the historical nomadic livestock grazing practices to a more sedentary system since the mid 20th century as a result of several major policy shifts by the central Chinese government. However, a nearly nine-fold increase in livestock numbers during a 56-year period (1947 to 2003) might simply overwhelm any other factor in contributing to overgrazing during the later half of the 20th Century. During the past five decades, rangeland productivity has declined $54-70 \%, 30-40 \%$, and $50 \%$ in the meadow steppe, typical steppe, and desert steppe grassland areas, respectively. In addition, there have been significant shifts in species composition as the percentages of perennial grasses and legumes have decreased with a concomitant increase in weedy species.

Desertification, a larger-scale phenomenon characterized by both biophysical and social causative factors, is prevalent across Inner Mongolia. Approximately $55-60 \%$ of the total land in Inner Mongolia is classified as desertified with tremendous losses of soils and soil fertility due to accelerated erosion.

\section{Projected Climate Change for Asia with Emphasis on Inner Mongolia/Mongolia Rangelands}

The International Panel of Climate Change 4th Assessment Report provided a synthesis of outputs from 21 climate models for Asia (Fig. 2). With a focus on the Mongolia and Inner Mongolia rangelands, the projections of a majority of these models is for increased annual temperatures in this region of $4.5-9.0^{\circ} \mathrm{F}\left(2.5-5.0^{\circ} \mathrm{C}\right)$ with increases occurring during both the winter and summer months. Precipitation shows an increase in winter months across the region, and a gradient of slight decreases in precipitation across the western desert steppe to a slight increase in annual precipitation across the meadow steppe to the east. The precipitation increase in winter is projected by most models to be higher than for the summer months.

\section{Possible Impacts of Climate Change on Landscapes and Land Uses \\ The Geographic Boundaries of Inner Mongolia and Mongolia Rangelands Will Likely Change}

With projected increased temperatures during both winter and summer seasons and slightly elevated annual precipitation mostly due to increased winter precipitation, there are projected changes in rangeland boundaries. Within Inner Mongolia, the warm temperate steppe, meadow steppe, typical steppe, and desert steppe regions across Inner Mongolia are projected to change. The meadow steppe might disappear, the typical steppe could be $55-75 \%$ of the present size, and the desert steppe could be $80 \%$ of the present area. However, the area of warm temperate steppe zone might actually increase substantially with projections of increases as large as 60-130\% of the existing area. With these potential reductions in grassland areas, projections are for two new types of rangelands in this region: an extreme desert and a warm temperate shrub grassland. In Mongolia, projections indicate the current zones will move northward due to the higher temperatures and increased aridity. By the end of the century, the mountain taiga and forest steppe area are projected to be reduced and replaced

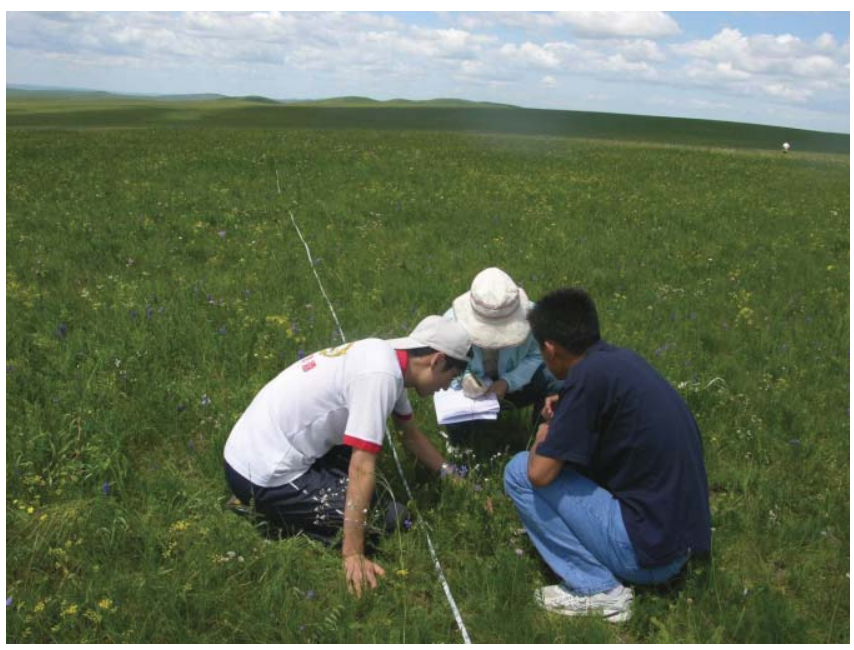

Graduate students from the Inner Mongolia Agricultural University, Hohhot, collecting vegetation data within the grasslands of Inner Mongolia. 

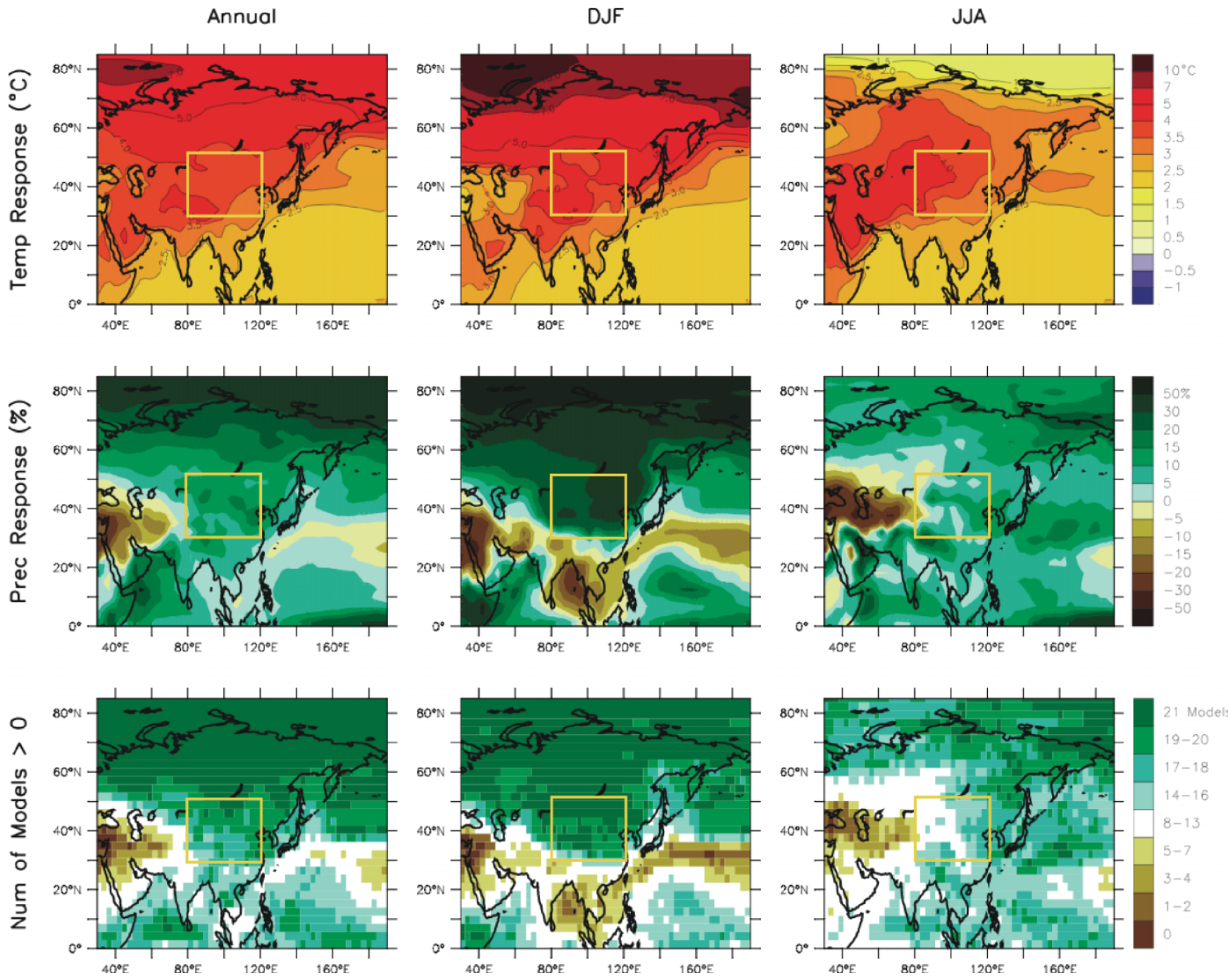

Figure 2. Temperature (Temp, C) and precipitation (Prec, \%) changes across Asia from various simulations drawn from 21 different climate models as summarized by the Intergovernmental Panel on Climate Change (used with permission; see www.ipcc.ch/ipccreports/ar4-wg1.htm). Bottom row graphs synthesize number of models creating projections for temperature and precipitation changes greater than 0 for annual, winter (December, January, February; DJF) and summer (June, July, and August; JJA) periods. Middle row graphs reflect precipitation changes for these periods, and top row graphs reflect temperature changes for these three periods.

by steppe vegetation. The steppe, desert steppe, and desert are projected to increase in size and shift northward.

\section{Net Primary Production (NPP) in Most Areas Is Likely to Decline}

Temperature increases are expected to elevate heat stress in plants, and reduced precipitation during the summer months will result in reduced soil moisture availability during the growing season. Recent research results from a long-term study in Inner Mongolia indicated that January-July precipitation is a primary climatic factor causing fluctuations in net primary production in the region.

Model predictions based on a $3.6^{\circ} \mathrm{F}\left(2^{\circ} \mathrm{C}\right)$ temperature increase and a $20 \%$ precipitation decline significantly reduced estimates of primary production. For instance, the
NPP of desert steppe declined by $17 \%$, and by $9 \%$ for the typical steppe.

Recent studies in Mongolia indicate that NPP will be reduced by $5-30 \%$ in the forest steppe and steppe zones by 2080. However, high mountain and desert steppe zones are projected to have higher NPP (25-75\%) due to higher temperatures in the high mountain zone and increased rainfall in the desert steppe zones.

\section{Water Availability Will Likely Be Reduced}

The combination of precipitation decreases and temperature increases would likely induce shortages of water resources. As a result, runoff into major rivers would likely decline, and some lake water levels would be reduced or even eliminated. 
Air temperature increase can increase the evaporation of soil moisture, but in regions that experience precipitation increases, evaporation losses might be offset. Overall, water use efficiency could increase under climate change predictions in the Inner Mongolia and Mongolia regions if both increased temperatures and seasonal precipitation are realized, especially in conjunction with higher atmospheric $\mathrm{CO}_{2}$ levels (see Morgan et al., p. 18-22).

\section{Soil Erosion Losses Are Expected to Increase}

Projected soil losses in grassland types with increased arid land vegetation would result with reduced soil cover. Undoubtedly, this would lead to increased wind erosion of soils from these rangelands. This would further exacerbate a soil erosion problem that is already pronounced across the region. This could be the most serious outcome of projected climate changes for this region in Asia.

\section{Nonnative Species Are Likely to Increase in Abundance}

Nonnative species are a typical problem in the rangelands with low productivity. However, Mongolian and Inner Mongolian rangelands seem to be relatively resistant to species invasion. There are few invasive plant species within this region. Important mitigating factors common to rangelands relative to species invasion, including minimal soil disturbance, high ground cover, and lack of dispersal vectors, could all change under these climate predictions.

\section{More Frequent and Prolonged Droughts}

Drought frequency and intensity are projected to increase over the continent of Asia. These events could lead to crop failures and food shortages that, in turn, could lead to reduced availability of supplemental feeds for livestock during drought periods. Given projected population

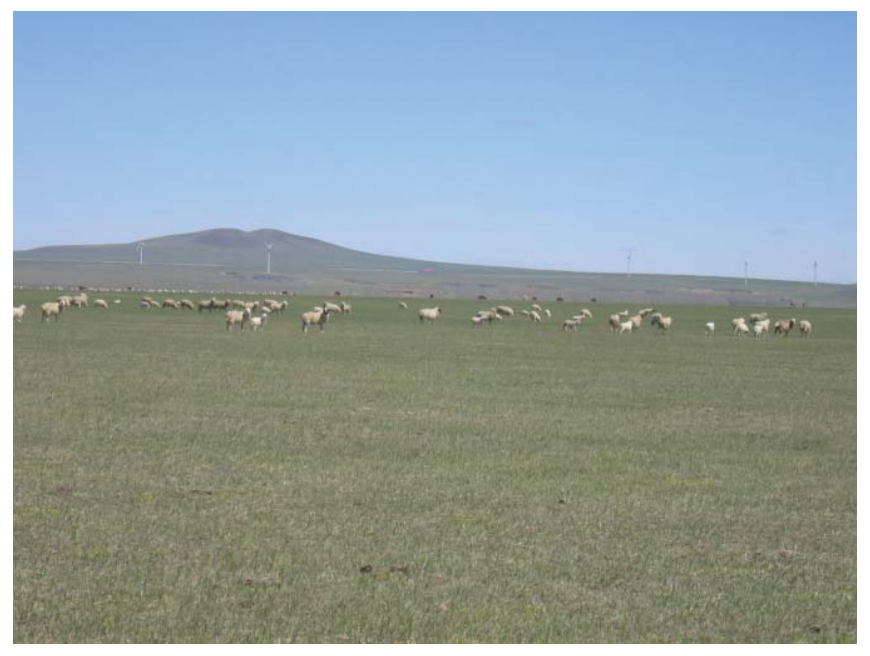

Sheep grazing within typical steppe grasslands near Dali Lake, Inner Mongolia. increases and continued increases in livestock numbers, the potential exists for continued degradation of the rangeland resource.

\section{Strategies to Cope with Climate Change}

The extent to which these rangelands have been subjected to excessive grazing by livestock in recent decades likely overwhelms any immediately observable effects of possible changes in climate. In addition, it is unlikely that application of simple principles associated with proper grazing management to match carrying capacity estimates will adequately address the problems now facing these humanlivestock-coupled pastoral systems. The issues embedded in these landscapes include poverty, social stratification, property rights, and policies developed by strong central governments. However, climate change projections could have significant impacts across this region, noticeably causing further decreases in NPP. Therefore, any future strategies for mitigating these impacts need to address classic rangeland management concerns of limited and highly variable forage production within an overwhelming context of economic and political changes, transitions from nomadic to sedentary life styles, growing food and fiber demands, urban expansion, an expanding need for these lands to provide additional goods and services, and the uncertainties created by a changing climate.

These issues and the projected climate change impacts highlight a need for comprehensive monitoring and forecast systems for these rangelands. From a monitoring perspective, both short-term and long-term monitoring are needed to improve decision making, reduce risk, and to develop adaptive management strategies. Livestock early warning systems that combine field data collection, simulation modeling, and remote sensing can provide information on current forage and near-term forage conditions to assist with stock/destock and movement decision making. Long-term rangeland health monitoring can allow detection of trends in the vegetation and soil resource, thus providing the means to assess the success of meeting management goals, as well as providing necessary information for adaptive management. Improved and long-range weather and drought forecasts would also assist producers as well as government in planning for drought and extreme climate events.

A community-based approach to planning and decision making will likely be needed for effective management on these communal lands and to provide a conduit for information flow from monitoring programs to scientists and governmental entities. Government could provide an increased role in development of monitoring programs, coordination of livestock movement during drought and winter disasters, improved information flow, and training for livestock producers on appropriate decision making. This will allow improved awareness of problems and more coordinated responses to changing climate and climate extremes. 


\section{Acknowledgment}

This paper was supported by the National Natural Foundation of Sciences of China, project number 30590382 .

\section{Additional Reading}

Batima, P. 2006. Climate change vulnerability and adaptation in the livestock sector of Mongolia. Assessment of Impacts and Adaptation to Climate Change (AIACC) Final Reports. Project No. AS 06. Available at: http://sedac.ciesin.columbia.edu/aiacc/ progress/FinalRept_AIACC_AS06.pdf. Accessed 2 March 2008.

Christensen, J. H., B. Hewitson, A. Busuioc, A. Chen, X. Gao, I. Held, R. Jones, R. K. Kolli, W.-T. Kwon, R. Laprise, V. Magaña Rueda, L. Mearns, C. G. Menéndez, J. Räisänen, A. Rinke, A. Sarr, and P. Whetton. 2007. Regional climate projections. In: S. Solomon, D. Qin, M. Manning, Z. Chen, M. Marquis, K. B. Averyt, M. Tignor, and H. L. Miller [EDs.]. Climate change 2007: the physical science basis. Contribution of Working Group I to the Fourth Assessment Report of the Intergovernmental Panel on Climate Change. Cambridge, United Kingdom: Cambridge University Press. p. 887-940.

Cruz, R. V., H. Harasawa, M. Lal, S. Wu, Y. Anokhin, B. Punsalmaa, Y. Honda, M. Jafari, C. Li, and N. Huu Ninh. 2007. Asia climate change 2007: impacts, adaptation and vulnerability. M. L. Parry, O. F. Canziani, J. P. Palutikof, P. J. van der Linden, and C. E. Hanson [EDs.]. Contribution of
Working Group II to the Fourth Assessment Report of the Intergovernmental Panel on Climate Change. Cambridge, United Kingdom: Cambridge University Press. p. 469-506.

Global Land Cover Characteristics Database. 2007. Version 1.2 and Version 2.0. USGS EROS Data Center Distributed Active Archive Center, Sioux Falls, SD, USA. Available at: http://edcwww.cr.usgs.gov/landdaac/glcc/glcc.html. Accessed 3 March 2008.

National Statistical Office-Mongolia. 2007. Mongolian Statistical Yearbook 2006. Ulaanbaatar, Mongolia: National Statistics Office. 401 p.

Okayasu, T., M. Muto, U. Jamsran, and K. Takeuchi. 2007. Spatially heterogeneous impacts on rangeland after social system change in Mongolia. Land Degradation E Development 18:555566.

A more extensive bibliography is available at http://www. rangelands.org/climatechange.shtml.

Authors are Research Scientist, Texas AEऽM University, 2138 TAMU, College Station, TX 77843-2138, USA, jangerer@ cnrit.tamu.edu (Angerer); Professor, Inner Mongolia Agricultural University, Hobhot, China (Han); Assistant Research Scientist, Texas AE'M University, 2138 TAMU, College Station, TX 77843-2138, USA (Fujisaki); and Supervisory Scientist, USDA/ARS Jornada Experimental Range, PO Box 30003, MSC 3JER, New Mexico State University, Las Cruces, NM 88003-8003, USA (Havstad). 